\title{
Wronging Future Children
}

\author{
K. LINDSEY CHAMBERS \\ University of Kentucky
}

\begin{abstract}
The dominant framework for addressing procreative ethics has revolved around the notion of harm, largely due to Derek Parfit's famous non-identity problem. Focusing exclusively on the question of harm treats what procreators owe their offspring as akin to what they would owe strangers (if they owe them anything at all). Procreators, however, usually expect (and are expected) to parent the persons they create, so we cannot understand what procreators owe their offspring without also appealing to their role as prospective parents. I argue that prospective parents can wrong their future children just by failing to act well in their role as parents, whether or not their offspring are ultimately harmed or benefitted by their creation. Their obligations as prospective parents bear on the motivations behind their reproductive choices, including the choice to select for some genetic trait in their offspring. Even when procreators' motivations aren't malicious, or purely selfish, they can still fail to recognize and act for the end of the parental role. Procreators can wrong their offspring by selecting for some genetic trait, then, when doing so would violate their obligations as prospective parents, or when their motivation for doing so is antithetical to the end of the parental role.
\end{abstract}

Keywords: future persons, parents, procreation, reproductive selection, role obligations

\footnotetext{
A $s$ reproductive technology progresses, procreators have increasing control over the procreative process. The use of in vitro fertilization (IVF), in particular, has enabled procreators to select for or against a range of genetic traits in their offspring. Through the use of preimplantation genetic diagnosis (PGD) in conjunction with IVF, procreators can test fertilized embryos for genetic conditions ranging from Tay-Sachs disease to cystic fibrosis. They can then use that information to decide which embryos, if any, they wish to transfer to a woman's uterus.
}

Contact: K. Lindsey Chambers <klchambers@uky.edu> 
The use of reproductive selection is most commonly used to screen against genetic disorders; however, in 2002, a deaf couple made the news for using PGD to select for a deaf child (Savulescu 2002). Couples with dwarfism have since followed suit (Baruch 2007: 255-258). In principle, PGD can be used in conjunction with IVF to select for any trait that has a genetic marker. So, as our knowledge of the human genome increases, so too does the potential for procreator selectivity.

The practice of selecting for a disability, particularly deafness, has polarized procreative ethicists. Advocates for disability selection appeal to the value of diversity, the importance of a shared culture between parents and their children, and the quality of life that persons with disabilities are able to have (Asch 1999; Barnes 2014). Opponents of the practice, on the other hand, argue that the child is harmed or made badly off by the selection, or that the procreators have failed in their duty to bring about some optimal state of affairs (Brock 1995; Davis 1997; Buchanan, Brock, Daniels, \& Wikler 2000; McMahan 2005; Savulescu \& Kahane 2009).

Amidst the debate surrounding the selection of disability, the potential badness or burden of the disability has been the focus, largely due to Derek Parfit's (1987) famous non-identity problem. Parfit argues that procreators cannot harm, and so cannot wrong, the persons they create, so long as those persons have lives that are not worse than non-existence. ${ }^{1}$ If, as he argues, some version of genetic essentialism is true, that is, if a person's identity depends on the particular sperm and egg from which she originated, then the person born with a congenital disease or disability could not have been brought into existence apart from her condition. If her procreators had taken steps to avoid creating a person with that disease or disability (e.g., by waiting to conceive, selecting different embryos to transfer, or using donated sperm or eggs), then a different person would have been created.

The crux of Parfit's non-identity problem rests on the metaphysical claim that any change in the procreators' actions will likely result in the creation of a different person. Locating a wrong to the person created is difficult if the procreators' actions, however otherwise objectionable, make the person they create as well off as she could be. If the deaf parents shouldn't select for deafness, it is not because it would be better for the deaf child. She would not exist if they had selected for a hearing child. The deaf child who results from their selection is made as well off as she could be by their selection, so even if their selection is wrongful, she doesn't seem to be its victim. ${ }^{2}$

On Parfit's account, if selecting for deafness is wrong, it's because selecting

1. Parfit (1987: 351-355) and Velleman (2008) both argue for a comparative account of harm. Hanser (1990) accepts that harm can be non-comparative, but he argues that it must involve a loss.

2. Thanks to an anonymous referee for stressing this point. 
for deafness fails to bring about the better of two possible states of affairs. Failing an impersonal consequentialist principle, however, does not explain how procreators could ever wrong their offspring. If anyone should have cause for complaint about procreators' actions, their offspring are prime candidates. Yet, the metaphysics of personal identity and harm seem to block our accounting for some personal or directed wrong to the offspring who results.

One way to resist Parfit's conclusion is to reject his assumption that wronging requires harming. ${ }^{3}$ Procreators might wrong their offspring by violating their rights, ${ }^{4}$ making them badly off (without harming them),${ }^{5}$ or acting on a principle that they (and others) could reasonably reject (Kumar 2003; Hurley \& Weinberg 2015). On a rights or interest-based account, whether the deaf child is wronged by her procreators' selection still depends on deafness being bad for the child - the very thing contested by disability advocates. ${ }^{6}$ Setting aside disagreement about whether having a disability, like deafness or dwarfism, is typically bad for the person who has it, whether the child has a special complaint against her procreators' selection still seems to depend on whether or not her own existence with the disability is worse than not existing at all.7 Especially if you think disability is a neutral trait, but even if you don't, it's a tall order to claim that persons with such disabilities don't have the opportunity to live full, flourishing lives. ${ }^{8}$ And even if the contractualist accounts are right and we are in

3. Another strategy is to salvage the notion of procreative harm. Harman (2004) argues for a different comparative notion of procreative harm, where the relevant comparison is between the child's state at birth and the typical or average state of human beings at birth. For Shiffrin (1999), the child's state can be a non-comparative or an absolute harm because it presents an obstacle to her agency.

4. Velleman (2008) claims that children have a right to a decent start in life. Davis (1997) and Feinberg (1980) argue that the child has a right to an open future. Woodward (1986) argues that you can wrong someone just by violating her rights, but in the case of procreation he's skeptical that a child has a right to decent start in life, or that whatever counts as a decent start in life precludes having a disability.

5. For Kavka (1982), you can't depend on principles aimed at individuals, because what's good for some individual can lead to uncontrolled population growth, which is bad for many future persons. The role framework I present can capture the collective good in tandem with the good of individual children (and their parents). Role obligations account for more than how this parent should treat that child, because social roles capture how parents in general should treat their children within the context of our wider social scheme.

6. McMahan (2005) and Barnes (2014) represent opposite poles of this debate.

7. Adams (1972) makes this point about our standing to complain about the world God has created. The world we live in at least seems to be less than the best possible world an omnipotent God could create. Do we, then, have grounds to object to God's failure to create the best of all possible worlds? Adams argues that we do not have such grounds because our existence depends on his not creating the best possible world. Perhaps God has acted wrongly, but God has not thereby wronged us.

8. After arguing that you can wrong someone without harming her when you've violated her rights, Woodward himself acknowledges that being born with a disability is not obviously a rights violation. See Woodward (1986). 
a position to criticize procreators for creating a person who will face some limitation, the child whose existence is inextricably linked to that limitation doesn't seem to have special standing to criticize them. ${ }^{9}$ We're left with an undesirable loophole for procreators: their selection, however otherwise wrongful, cannot constitute a wrong to the child that's created as a result.

In what follows, I will show that a role-based framework can be used to explain both how procreators could wrong their offspring without harming them and why their child has a special complaint against her procreators for that wrong. Procreation results not only in the creation of a new person, but also in the creation of a distinct moral relation between procreators and their offspring. My account of procreation treats the relation between procreators and their offspring as central to the morality of procreation. Procreators usually expect (and are expected) to parent the persons they create, so we cannot understand what procreators owe their offspring without also appealing to their role as prospective parents. The role of parent, like many social roles, is not just a matter of convention. It generates moral obligations that constrain how parents may treat their children, including, I will argue, how they become parents to begin with.

I will show that procreators assume the parental role and its subsequent obligations when they set out to create a child. ${ }^{10}$ Procreators can wrong their children by failing to be guided by those obligations in their procreative decisions, even if they don't violate their parental obligations once their child is here. ${ }^{11}$ The morality of selecting for disability, then, depends on whether the procreators' motivations are consistent with their obligations as prospective parents, not simply whether the disability is a good or bad trait to have.

9. On Kumar's (2003) contractualist account, the deaf offspring could complain that her procreators, qua caregivers, didn't act on a principle (what he calls Principle M) that took her prospective disability as something to be avoided. It may be true that, in failing to act on Principle $\mathrm{M}$, the procreators could be charged by anyone for their failure to act well as caregivers. What is difficult to see, however, is how their deaf offspring could have special or personal grounds for complaint. She only exists because her procreators did not act on Principle M. Because Principle $\mathrm{M}$ is a wide-person affecting principle, not a narrow-person affecting principle, it can't capture a special wrong to that child. Hurley and Weinberg (2015) also offer a contractualist account of procreative wronging, but their account locates the wrong as a violation of the offspring's secondpersonal claims on her creators. My account is similar in spirit to Hurley and Weinberg, in that role obligations also situate moral actors in different kinds of relations to other persons, and those relations in turn affect the claims those persons have on them. You needn't be a contractualist to accept the role framework, but the role framework is amenable to the second-personal standpoint as a way to specify the second-personal claims persons have on one another when they occupy role relationships.

10. For my purposes, this includes persons who will be neither the genetic nor biological parent of the child. A person who uses a gamete donation and a surrogate will count as a procreator in virtue of setting out to create a child.

11. Sandel (2007: 45-62) locates the wrong in what happens later in the parent-child relationship. Having bad parental attitudes when procreating risks bad parenting down the line. 


\section{Role Obligations}

Social roles shape the moral context of our lives. What a person should do depends in part on the kinds of relations she stands in to other persons. I have different claims on and obligations to my parents, my friends, my students, and my landlord, because I am in different kinds of relationships with each of them and them with me. To know how we ought to treat each other, we must know more about what those roles, or social relationships, require of us. In what follows, I will rely on something close to the standard view of role obligations: role obligations are grounded in the end or purpose that the role serves. ${ }^{12}$ When a social role serves some moral end or purpose, a person who occupies that role can, in virtue of occupying that role, have moral obligations to the recipients of that role. ${ }^{13}$

Some roles align with occupations (doctor, teacher, police officer), others primarily with relationships between persons (friend, spouse, parent), or between persons and organizations (citizen, PTA president, Rabbi). These social roles are constituted by norms or standards of behavior that depend on the end or purpose of the role. ${ }^{14} \mathrm{~A}$ teacher's end is (roughly) to educate persons in a particular field or subject, and the norms associated with being a teacher will capture the training, skills and practices that are necessary to do so, such as getting an adequate education or having the right disposition. A physician's end is to give assistance to persons in medical need. A spouse's end is less clear. Perhaps the end of being a spouse depends on the end of marriage, if there is one, or the end of the relationship itself, whatever that is for the persons in it. ${ }^{15}$ The end of a citizen might be the maintenance of the state or, perhaps, to make the state more just.

Among the social roles a person might occupy, fiduciary roles serve a distinct purpose. Fiduciary role actors take on responsibility (often both legal and moral) to act in the interest of some dependent person(s). Fiduciary roles include those

12. Cohen (1967) identifies social roles as those categories which correspond to special rights or duties for the person who occupies the role. Cohen's definition may be narrow, but for my purposes, the roles I'm interested in are just those that do genuinely have corresponding rights and obligations, because those roles contribute to some moral end. Doctors and teachers will be examples of such roles, as will parents. Gang leaders and drug dealers are less likely to qualify. They may in some sense count as social roles, but they won't be morally justified social roles, or roles with a moral rationale.

13. Horton (1992: 55-58) and Simmons (1996: 30) call this the 'external justification' of institutional obligations. The moral force of institutional obligations depends on there being some external (not from the institution itself) moral rule or duty that requires its performance. Such roles enable our cooperation in discharging natural or general moral duties.

14. Some of these norms are merely socially enforced, while others may be legally regulated or tied to employment.

15. Marriage involves a serious commitment, but what that commitment amounts to might vary between couples, from monogamous to open marriages. 
of social workers, lawyers, physicians, investment advisors, trustees, teachers, parents, babysitters, etc. Persons in these roles take on responsibility to act for the sake their clients, beneficiaries, patients, students, and children, within some specified context. Investment advisors act for the sake of their clients' financial interests; physicians act for the sake of their patients' medical interests; social workers for the sake of some children's welfare, etc. ${ }^{16}$

Where a social role contributes to our satisfying some collective moral duty, as many fiduciary roles do, that role can be seen as conferring moral obligations on the persons who occupy it, not merely social conventions or expectations. Even if we all have a duty to, say, care for the young or sick, some people will be better able to help particular persons because they are near them, in relationships with them, or have the appropriate resources or skill sets to help them. Social roles can track these differences and enable us to divide our moral labor in a way that helps us to collectively meet our obligation to help one another.

When role actors fail to meet their role obligations, they don't just act wrongly, they also alter the moral quality of the relation they stand in to the recipients of their actions. When a role actor's failure is a failure to meet an obligation she has to some role recipient, that failure constitutes a wrong to that role recipient.

Consider the following case of a role actor's negligence that is similar in structure to Parfit's non-identity cases.

Lazy Landlord: A landlord manages a building that is not up to code. She has a unit that is unoccupied. She could either fix the code violations and then rent the unit to some tenant a few months later, or she could rent the unit to some tenant now. With the high turnover of rental properties in the city, she is likely to have a different tenant if she fixes the code violations before renting it out. The landlord decides to ignore the code violations and rent the unit immediately.

The tenant who moves into that unit may be happy to rent it despite the code violations. Perhaps the tenant is able to fix them himself, or would have had to live much further from his work if he couldn't rent it, or even been homeless had he not been able to immediately move into that unit. Though the unit is not up to code, it is livable, and the tenant may well be better off living there than nowhere at all. Like in Parfit's non-identity cases, if the landlord's negligence is wrongful, the tenant who occupies the apartment in light of it doesn't seem to

16. Contrast the role of physician with the role of medical researcher. A physician has a fiduciary responsibility that the researcher lacks. Joffe and Truog (2010), for example, argue that because physicians and medical researchers occupy different roles, they are subject to different standards for their interactions with patients (e.g., informed consent standards). 
be its victim, not if we view the case through the lens of harming. The obligations landlords have to their tenants may capture what is typically best for landlords and tenants generally, but they don't align with what is best for this particular tenant. Even if we could all criticize the landlord for her negligence, if the tenant himself is no worse off, and if nothing bad comes of it down the road, does he lack any special standing to complain about her negligence?

Occupying the role of landlord puts the landlord in a moral relationship with her tenants: she has a duty to them to ensure that the units she rents meet the standards for safe, accessible housing. Her duty is generated by the role she occupies, a role that is itself partly a matter of social and political convention, but that nonetheless has a moral dimension. To be a landlord is to occupy a kind of fiduciary role. You take on responsibility for the habitable housing of your tenants. You may benefit from occupying this role (e.g., collecting rent), but part of the role is still keyed to the interests of your tenants. What it takes to make an apartment habitable may be costly to the landlord, but to be a (good) landlord is to condition one's profit-seeking on what will also meet the end of providing adequate housing to one's tenants. The landlord's failure to do her job-bringing the unit up to code-is a failure in her role as a landlord, and by extension, a failure to her tenant. Though that particular tenant would have been worse off had the landlord done her job well, he is still wronged by the landlord's failure to fulfill her duties to him as his landlord.

Role obligations operate a level up. They constrain and guide the kinds of actions that tend to help or hinder the purpose of the role the actor occupies. Those standards are informed by facts about what effects certain actions typically have on other persons, but they do not cease to apply even when happenstance intervenes in an unforeseeable way for individuals (for better or for worse). That the tenant happens to be made better off doesn't absolve the landlord from her negligence, because her obligation to him was to act in accordance with her role, not to make him better off. If procreators occupy a role with respect to their offspring, then it's possible that they, like the landlord, can wrong their offspring just by violating their role obligations, whether or not their offspring are ultimately made better or worse off by their actions.

The landlord may also owe her duty to act well in her role to all the persons who are members of the social institution in which she operates. Her wrong, then, may not just be to her tenant -it might be to all of us. Nonetheless, her action still constitutes a distinct wrong to the person she serves, even if it is also a wrong to other persons. The landlord owes her duty to some role recipient(s), not merely to herself, to all of us, or to no one at all, partly because her role puts her in a relationship with a particular person. Role relationships are constituted by norms keyed to the end of the role itself, but a failure to meet those norms can do damage to a role relationship with a particular person. The role actor's 
wrong has a personal component-it alters the moral relation she stands in to the particular role recipient she serves. ${ }^{17}$

In the landlord case, the damage to the role relationship is not dependent on the role recipient's interests or welfare being set back. Rather, the damage is constituted by the role actor's failure to treat the recipient well qua role recipient, a failure which is morally problematic apart from whatever other consequences ensue. In this way, role failures resemble more general moral failures. My duty not to lie, for instance, is a duty I have to everyone, and insofar as you are also a person, it is also a duty I have to you. If I lie to you, perhaps I damage our general communicative practices and so harm all the members of our speech community, but importantly, I also damage our moral relationship. If I fail to treat you well qua fellow person, then, whether or not you are also made badly off by my lie, I have done damage to something important, namely, our standing as equally valuable persons. ${ }^{18}$ I treat you as if your value as a person is subordinate to your value as an instrument to my own ends, thus creating a relationship of inequality between persons who ought to stand toward one another as moral equals. ${ }^{19}$

Roles that have moral ends introduce a specification of this same kind of relationship. The landlord does not just owe her role obligations to her tenant qua fellow person, she also owes them to him in virtue of her role relationship to him. She treats him as an equally valuable person, not just by observing her general moral duties to him, but also by discharging the particular duties she has in virtue of her occupying a role in which she assumes responsibility for providing a particular kind of service. When she acts for her own ends rather than the end of her role, she subordinates the value of the role recipient to the value of her own ends. In doing so, she damages the moral relationship between them, whatever the outcome for his eventual wellbeing.

When we evaluate the landlord's action through the role-based framework, then, we can explain how she has obligations to someone even when that person's identity is as-of-yet undetermined, and even when the identity of the person to whom the obligations are owed itself depends on what the role actor

17. May (2015) canvases three kinds of directed duty accounts and the problems that befall them. My view approaches what May calls a "moral nature" account, though I do not take this paper to be an argument for it.

18. If you think that wronging must involve harm, you might consider damage to the moral standing we have toward one another to constitute its own kind of harm, one that cannot be fully captured by appeal to welfare.

19. I am appealing here to something like Kant's (1997: 38) requirement that we treat persons as ends in themselves, never merely as a means. However, you might fill out the underlying moral story differently. What is worth noticing, though, is that role violations can mirror the kind of wrong that shows up when we fail our general moral obligations, however those obligations are ultimately understood. 
does. The lazy landlord's obligation to bring her rental unit up to code is not an impersonal duty even though she has not yet rented that unit to a particular tenant. Which person becomes her tenant depends on a variety of factors: when and where she lists the unit, the unit's price, the dynamics of the rental market, the needs of potential tenants, etc. Given the fast turnover in the rental market she's in, if she takes more time to fix the unit, then she will have a different tenant altogether. But whichever person becomes her tenant is still the object of her actions, qua landlord, considered over time. If she fails to meet her obligations as a landlord, then that failure constitutes a directed or personal wrong to whichever person becomes her tenant, because it damages the landlord-tenant relation between them.

Herein likes the upshot of appealing to the structure of role obligations for procreation cases: if procreators occupy a role vis-à-vis their offspring, then what obligations they owe them depends on the end of the role they occupy (if any), not the identity or eventual wellbeing of the offspring they bear. And like the landlord who didn't need to be in a landlord-tenant relation at the time of her wrongful action to count as wronging her (future) tenant, if procreators occupy a role with respect to their offspring, then they can have obligations, qua role actors, to whomever they create. If they fail to meet those obligations, they damage the moral quality of the relation between them and their offspring. As occupants of that relationship, their offspring have a special interest or ground for complaint when that relationship has been damaged.

You might think, however, that the explanation for the wrong in landlord example isn't that she failed to meet her role obligations, but that her actions risked harming someone. While it is true that the lazy landlord's failure to conform to the standards for her role put her tenant at risk of harm, acting in ways that put others at risk for harm isn't always a violation of a moral duty. The risk itself is made morally salient because the landlord occupies a particular role. If my neighbor solicits my help in fixing the electrical work in her home, I may well act in ways that risk harming her. But it is not clear to what extent I am responsible for that risk. At the very least, I do not have the kind of responsibility toward my neighbor that a landlord would have. The mere fact, then, that the landlord's role failure put a role recipient at additional risk of harm isn't doing all the work. That she is acting as a landlord is part of what makes her morally accountable for that risk.

More importantly, we can account for the landlord's wrong by appealing to her choice structure as a role actor without appealing to any risk of harm. The landlord takes her own interests to be guiding, or to be the end for which she acts, when she is supposed to be acting in her role. Her own interests and ends matter, but they cannot be prioritized over her role obligations when she acts as a landlord. To act in one's role and fail to meet one's role obligations may also 
risk harming the person to whom those obligations are owed, but prior to that harm there is already a problem: the role actor treats her own personal interests or ends to take precedence over or to excuse her from the obligations she has to others in virtue of the role she occupies.

\section{Entering Role Relationships}

The question, then, is what role, if any, procreators occupy with respect to the persons they create. The obvious candidate is the parental role. As many actual procreators are keenly aware, they aren't strangers to the persons they create. Procreation is typically the beginning of a deep and life-altering relationship: the parent-child relationship. It is often for the sake of this relationship that many procreators procreate at all. Procreators aren't merely causing the existence of an additional person, they are creating a person to whom they will stand in a particular kind of relation - that of a parent to a child. But unlike the landlord, who already has a property to-be-rented and so plausibly occupies the role of landlord before she rents the property to particular persons, potential parents don't seem to occupy the parental role until they become actual parents.

A general feature of roles is that a person can act in a role-and so be subject to its obligations-before she enters a particular role relationship. Like the lazy landlord, role actors are subject to role obligations that bear both on how they prepare for their role and how they enter role relationships with particular persons. Doctors, teachers, lifeguards, pilots, etc., all take steps to assume their respective roles, and those steps are themselves guided by the standards or norms for those roles. These professionals go through training, certification, and other preparatory measures before they treat patients, teach students, guard pools, fly passengers, etc. Though occupying these roles connects these professionals to the persons they eventually serve, the roles themselves extend beyond particular role relationships. Role actors often operate in their roles with respect to more than one role recipient, and role obligations constrain how they can assume their role with respect to particular role recipients in a morally decent way.

Consider an analogy to romantic relationships, which have a moral dimension but not necessarily an explicitly moral purpose. For romantic relationships, something goes wrong when a con artist picks a mark to swindle out of money by pretending to engage in a sincere romantic relationship or when the teenage couple dates only because one of them is trying to win a bet. If romantic comedies have taught us anything, it is that there can be something wrong with how a relationship begins, not just how it goes once it is underway. Both the con artist and teen misrepresent their own feelings and commitment to their partners, and in doing so, they wrong their partners - not just when the relationship sours, but 
when they enter the relationship under false pretenses. Should the con artist and the teen fall in love with their respective partners, their relationships are nevertheless marred by their objectionable beginnings.

A relationship's beginning is as much a part of the relationship as its middle or end, and though persons in relationships may acquire more or different obligations as a relationship progresses (like when two persons progress from dating to being married), that does not mean that there are no obligations that bear on how the relationship gets started. Romantic relationships are about mutual admiration and love, not just once they are underway, but also in their conception. Beginning a relationship in an inappropriate way can damage its moral quality whether or not the relationship suffers in other ways down the line. The relationship between parents and their children, like all relationships, can also begin badly without thereby being a bad relationship overall. If parents enter the parental role in ways that violate the obligations they have to their future children qua parents, then, even if they ultimately have a good relationship with their children, they have still wronged them.

That we think prospective parents are constrained by parental obligations in how they become parents is evident in our treatment of prospective adoptive parents. We subject adoptive parents to a screening process - they must have sufficient financial means, a safe home, a clean background check - before they are permitted to adopt. That we do not do the same for prospective biological parents does not reflect that biological parents should not be prepared to become parents before procreating, nor that they do not often take steps, as adoptive parents do, to ensure that they are as ready as they can be to become parents. ${ }^{20}$ To become a parent without also ensuring that one is prepared to act well as a parent is a mistake, and that mistake constitutes a wrong to the child one eventually parents, however well one parents down the line.

To see how prospective parents can violate their parental obligations in how they become parents, consider a modified version of Gregory Kavka's (1982: 100-101) slave child case.

Contrite Slave-Child Adopter: A wealthy man pays a couple $\$ 50$,ooo to create a child that will be transferred to him at birth as his slave. Upon holding the child in his arms, the wealthy man has a total change of heart. He does not raise the child as his slave. He raises the child as any good parent would raise their child.

20. Lafollette (1980) argues that prospective parents should be licensed. Though parental licensing schemes face a number of feasibility issues in their implementation, the normative claim that parents should be adequately prepared to become parents is not contested. 
In Kavka's original case, the wealthy man has no change of heart, and the question of interest is whether the procreators wrong the slave child by creating her under such a contract, not whether the wealthy man has wronged the child. Kavka suspects we would be outraged by the couple's action, but he thinks we cannot locate a wrong to the slave child because, as in other non-identity cases, that particular child's existence depends on the couple's entering the contract with the wealthy man. In Kavka's case, our outrage at the couple is primed by the suffering the slave child will face. But suppose that suffering never comes to pass. Suppose the wealthy man is transformed when he meets the child. What can we make of his actions vis-à-vis the child he has taken into his care? If he doesn't actually enslave the child, if he is a good parent to her, has he not wronged her? If upon learning the circumstances of her birth she felt betrayed by him, would her reaction be justified? After all, she wouldn't exist if he hadn't commissioned her conception.

Though it's better that the wealthy man had a change of heart than not, we can still locate a wrong to the child. That wrong doesn't depend on her suffering later; the wrong depends on how the wealthy man became her parent. He entered the role of parent with the end of enslaving the child he received. He may not have thought of himself in the role of parent or caregiver, but that doesn't mean he hasn't become that child's parent. ${ }^{21}$ In the case of adoption, social conventions make it the case that, by taking the child into his home, he assumes the role of parent. His acquisition of the child excludes others from taking up the child's care, so he cannot take the child without also incurring responsibility to be that child's caregiver or parent.

Even if the wealthy man parents the child well once she's here, we can still object to the way in which he became her parent. He became a parent with the end of treating the child as someone who would serve his interests. He took on the responsibility of caring for the child with no intention of discharging that responsibility. And though the wealthy man's case may be extreme, it's an instance of a more familiar failure: he became a parent without considering whether he was capable of or willing to meet the obligations he would have as a parent. His later change of heart doesn't absolve his bad motives. He took on responsibility for a child without also having the end of caring for the child. His end of adopting a slave child constitutes a wrong to the child he acquired, independent of any further bad treatment of her.

21. Unlike Sciaraffa (2011), I don't think we need to identify with a role for it to be binding once we're in it. The wealthy man can count as assuming the parental role even if he doesn't at the time see himself as entering the parental role, because what it takes to assume a role is partly a matter of social convention. In this case, excluding others from caring for the child by taking the child into his home counts as assuming responsibility for that child's care, even if the wealthy man had no intention of caring for her. 
And though the wealthy man didn't think of his contract with the couple as a means to becoming some child's parent, many procreators do think of procreation as a means to becoming parents. Importantly, though 'procreator' is often used to indicate persons who become the biological or genetic parents of some child, I am using 'procreator' to include any person who sets out to create a child. A procreator might do so through the use of a sperm or egg donor, or a surrogate, and so might not be genetically related to the child or biologically involved in the child's creation (e.g., as a gestational mother). The wealthy man, in this sense, is a procreator. He doesn't adopt a child who already exists; he brings it about that a new child is created. Even though his causal connection is less direct than the couple he hires, he still sets out to a create a child, with their help, in order to take the child into his home. And while there are interesting questions surrounding the obligations and rights of persons who assist procreators, not everyone who causally contributes to a child's existence does so in order to parent that child. ${ }^{22}$

In what follows, I am primarily interested in persons who intentionally set out to create a child in order to parent that child. ${ }^{23}$ On most accounts of how persons incur parental obligations, procreators who make use of reproductive technology typically fit the bill: they intend to create a child to parent, they bear some costs or do work associated with creating a child, and they are (at least partly) causally responsible for the child's existence. ${ }^{24}$ Procreators who select for the traits of their children don't just find themselves in possession of a child to parent, they intentionally put themselves in the parent-child relation with a

22. The couple in the wealthy man case might also incur obligations to the child (e.g., to not give the child to the wealthy man as his slave). In what follows, it remains open that donors and surrogates also incur role obligations to the children they create. Perhaps they incur parental obligations, or perhaps they incur different role obligations altogether.

23. Blackstone (1803: 435) influentially claims that the mere act of creating a child incurs a responsibility to parent that child. Archard (2010) also gives a causal account of parental obligations. By causing the child's existence, you incur a responsibility to ensure that the child is parented, but that does not entail that you must be that child's parent.

24. The exception, here, would be genetic accounts of parenthood, like that offered by Hall (1999). On Feldman's (1992) labor-based account, where persons who bear the costs of parenting count as a parent, procreators become parents via the work and resources they put into creating the child. Hill (1991) and Parker (1982) argue for an intentional or voluntarist account, where you can become a parent by way of intentionally bringing about the child's existence (even if indirectly). Thompson (2005) and Millum (2010) both give role-based accounts of becoming a parent, where social conventions partly determine what counts as a parent. My account combines an element of the intentional, causal, and role-based accounts: persons can become parents by setting out to do so, and what actions count as 'setting out to do so' (e.g., procreating, adopting) is partly a matter of social conventions that might vary across societies. And though some of those conventions may not be settled with respect to actors who assist procreators (e.g., whether acting as a surrogate counts as assuming the parental role), the persons who commission the creation of a child are socially expected to at least be prepared to care for that child. 
child by creating her. The actions they take to purposefully enter that relation plausibly count as their assuming the parental role. If anyone has obligations to some future child as prospective parents, it's the persons who set out to become her parents. ${ }^{25}$

\section{Procreation Cases}

The wealthy man's motives were explicitly malicious. He commissioned the creation of a child for the sake of enslaving her. And though it's possible that procreators could be similarly motivated, the difficult cases aren't as simple as that. Consider one of Parfit's (1987: 358) non-identity examples, the case of the 14-year-old girl who wants to have a child. The girl is likely to give birth to a child with a clean bill of health, but many people still think it would be better for the child to be born to a parent who is herself better prepared to parent him. Parfit claims that the girl does something wrong in giving the child she creates a bad start in life, but that wrong is not directed at the child himself.

From within the role-based framework, the 14-year-old girl should wait, not because the child she would have at 14 would not have a life that is worth living (the bad start is not so bad), but because she is not yet ready to be a parent to that child. Acting well in the parental role can sometimes require that a prospective parent refrain from putting herself into the parent-child relation, either at a certain time or with a particular child, until she is adequately equipped to discharge her parental obligations. Even if the child she would conceive now would be as well off as he could be, she will still have wronged him if she is not capable of discharging her parental obligations when she becomes his parent. And even if she is capable of being an adequate parent now, if we take the case as Parfit stipulates it, the girl doesn't consider whether she will be able to parent her child well when she decides to conceive. She enters the parental role with a kind of blind optimism. Her risk might not end badly for the child's welfare, but her failure to consider the kind of relation she will enter with her child - and what it will demand of her-is itself a failure to act well as a prospective parent. ${ }^{26}$

The woman in Parfit's (1976) medication example makes a similar mistake.

25. It's important to note that some of the divide between accounts of parenthood are driven by disagreement about how persons acquire parental rights. I am giving an account of how someone acquires parental obligations, but the two might not always overlap. Having an obligation to the child does not guarantee that one acquires a corresponding right to parent that child.

26. Woodward (1986: 815) describes this kind of procreative negligence as akin to making a 'risky promise.' The 14-year-old girl takes on obligations that she is not well-positioned to meet. Like promising to do something you suspect you can't make good on, or making a promise without considering whether you can fulfill it, procreators should not procreate if they cannot also discharge the obligations that come with parenting. 
The woman's medication causes moderately severe, irreversible birth defects (e.g., a shortened limb). She doesn't need to take the medication permanently. In fact, in just a few months, she will no longer need to take the medication at all. If the woman intends to conceive, then she can either conceive now, while taking the medication, or wait a few months and conceive while no longer taking the medication. To most people, it seems clear that the woman should wait the three months. ${ }^{27}$ She is in a position to determine whether she will bring into existence and parent a child who will likely have a serious birth defect, a condition that should bear on the woman's deliberation about whether or not to conceive.

We can disagree about the specific content of parental obligations, even the exact end of the parental role (e.g., the child's happiness, wellbeing in a broader sense, or autonomy), but if the woman conceives now just because she prefers to have a child sooner, then the woman has failed to take seriously what she owes the child as his parent. She should at least consider what her offspring's prospective disability or birth defect will mean for him and his life. If she determines that he could live a full and happy life with the birth defect or disability, then that should show up in her deliberation about what to do. If she simply takes her own timing preference to be sufficient justification for conceiving now, whatever the cost for the child and without consideration about whether she is prepared and willing to care for a child with a disability or birth defect, then she makes a mistake as a prospective parent. The problem isn't just that he has a disability or a birth defect, but that his procreator took her own desire to procreate now to be sufficient grounds for creating him without considering what was in the interest of the child and whether she was prepared to parent that child well.

In both the medication example and the 14-year-old girl example, as they are stipulated, the procreators have only self-regarding motives. They assume the parental role without any regard for the interests of the person they will parent. In these cases, the procreators seem to subordinate the interests of their offspring, as their children, to their own desire to conceive at a certain time. And though there may be reasons in both cases for the procreators to conceive now that includes their deliberating well about what they owe their offspring as their creators, that is not what is happening in the cases as they are described.

We needn't locate the wrongfulness of their actions in the bad state of their offspring, or, like Parfit, deny that there's any wrong done to the offspring. Focusing on the resulting harm (or lack thereof) can cause us to overlook an important moral feature of both situations: the motivations behind the procreators' actions. Procreators, as prospective parents, should not intentionally create a person they cannot or do not intend to care for (the wealthy man), and they should not let

27. Of course, not everyone shares the intuition that it would be wrong for the woman to conceive while on the medication. Thanks to Harry Brighouse for raising this point. 
their own interests fully determine their procreative choices (the 14-year-old and the woman on medication).

Part of occupying a role is acting with that role in mind, so it matters how we fill out the procreator's motivations. A role actor must not only perform the actions required of her, she must also act for the sake of her role's end. That is, role actors should take their role obligations to be action-guiding. They fail to act well as role actors if they only conform to their role obligations by accident. Part of the diagnosis of the lazy landlord and wealthy man's failures is that they took their own interests to be sufficiently action-guiding when acting in their roles. The landlord does so in spite of a recognition of what her role requires, and the wealthy man does so because he fails to acknowledge that his acquisition of the child counts as assuming the role of a caregiver. A role actor needn't pursue her role's end exclusively, but she must make her role's end a condition of her actions. If pursuing her own interests would preclude her meeting her role obligations, then she shouldn't enter that role. And even if pursuing her own interests is compatible with meeting her role obligations, she must act for her role obligations, not just her own interests.

The wrong these procreators do to their children is best understood in terms of the resulting moral relationship between them. Parents assume primary responsibility for meeting the needs and interests of their children, often at the cost of their own interests. For a prospective parent to enter the parent-child relationship with no regard (or insufficient regard) for the parental obligations she has to that child is to make a grave mistake as a parent. Her action counts as assuming a role with respect to another person while at the same time taking her own desires or interests to be the ultimate guide for what she does. In doing so, she treats her child as if he were just a means to her own ends rather than as a person for whom she is assuming a special kind of responsibility. She thereby damages the moral relationship between them, and, whether or not he is also harmed or made badly off, he has grounds for complaint against her for her failure to act well as his parent.

Suppose, though, that the procreator's motives are more complicated. In modified versions of the medication example, given first by Robert Adams (1972) and later by Jeff McMahan (2005), a procreator conceives while taking medication with the explicit purpose of parenting a child who will have a disability. In both cases, the procreator wants to raise a child with a disability because she welcomes the prospect of raising a child who will be more dependent on her care. The procreator isn't negligent with respect to her parental responsibilities. She understands exactly what will be required of her if she parents a child with a disability, and she acts in order to take on that responsibility.

On one interpretation of this case, the procreator is almost as selfish as the wealthy man. She takes her own interest-to parent a child who will be more 
dependent on her care than a non-disabled child-as action-guiding, without regard for what's in the best interest of the child she creates. The procreator might (rightly) think that she would be an excellent parent to a child with a disability, but her interest in being such a parent must be conditioned on, or constrained by, what would be in the child's interest. That's not to say it's not in the interest of a child who cannot exist apart from his disability to be created, just that the procreator doesn't make the child's interest her end. To become any child's parent is to take responsibility for meeting the child's needs. Whatever other benefits procreators or parents hope to get from being parents, benefits which might motivate their wanting to become parents in the first place, once they're in a position to enter the parental role, they should take their prospective child's interests to be action-guiding. ${ }^{28}$

But suppose we interpret the case above more charitably. Suppose the procreator acts both for the sake of her interest in having a child with a disability and for the sake of the child. She may think that the very trait she wants her child to have - to be more dependent on her over time-is also good for the child. Perhaps they'll have a closer relationship because his dependency will enable her to love or care for him better than she would another child, or perhaps she thinks he will have access to unique experiences because of his disability. On this interpretation, she gives a great deal of thought to what would be good for her child. If she fails to act well as a parent, then it's not out of maliciousness, selfishness, or negligence.

Even in this version of the case, the procreator still makes a mistake. Her mistake is not a lack of regard for the child, but a misunderstanding of what the parental role is ultimately for. ${ }^{29}$ The purpose of the parental role is not simply to make parents and children happier, or to be a source of love or support for them both, as if parents and children entered their relationship as equals. The parentchild relation is one of initial dependence, but at least one end of the parental role is to eventually bring the child out of his dependent state (Schapiro 1999). Parents are meeting a moral need: to care for persons who cannot yet operate

28. People might assume the parental role for a variety of reasons, many of which may make no reference to the moral status and needs of the child. However, once a person assumes the role of parent, she incurs the obligation to discharge the duties that attend it. Hannan and Vernon (2008) make this point about other roles. A person may become a doctor because it fits with her other interests or her overarching life plan. But once she is a doctor, her interests in being a doctor are overruled by obligations that attend the role of being a doctor (obligations which are primarily determined by the interest of patients). On my account, those role obligations also bear on how they assume those roles.

29. My account is similar in spirit to Wasserman's (2005) account, though it is more demanding on prospective parents. It is not enough that prospective parents be concerned with some good of the future child. They must meet their parental obligations to that future child, even before she exists. 
in the world as independent agents so that they can become such agents. $3^{\circ}$ And even if you think we shouldn't rush a child's maturation, or that the parent-child relationship delivers goods beyond the child's eventual independence, a guiding aim of parenting is to work toward the child's growing up (Brennan 2014).

The parental role, like many fiduciary roles, is not meant to keep the child in a dependent state. Just as a physician who keeps her patient sick in order to continue providing her with medical assistance fails to act well as a physician, a parent who keeps her child a child fails to act well as a parent. Parents may never stop being in a relationship with their children, but good parents work toward their children's not needing to be parented anymore. We expect more from parents than their love, especially because their love doesn't always lead them in the right direction. Procreators who purposefully create children who will have a harder time becoming independent-however selfless their motive-act antithetically to the end of the parental role. This is a parental failure whatever the trait selected. ${ }^{31}$

Consider now the deaf parents from the outset. On the role-based account, whether it is permissible to select for deafness isn't fundamentally about the 'badness' of being deaf. The morality of their decision depends on what the deaf parents are selecting deafness for-is it their own desire to have a child like themselves? Is it to be better positioned to parent the child they create? Or a combination? It matters whether the reason behind their selection tracks or aligns with the end of being a parent. ${ }^{32}$

Deaf parents might select for a deaf child because they see deafness as a positive trait that would enrich their child's life. The Deaf community has developed its own social practices-languages, schools, rules of etiquette, technology, literary and storytelling traditions - that are shaped by the needs and interests of deaf persons (Dolnick 1993; Mindness 2006). Being part of the Deaf community gives the child access to a rich cultural heritage. Selecting for a deaf child so the child will be part of that community can be a choice made for the sake of the child's interests.

30. Reich (2002) notes that we don't leave it fully up to parents to raise children. We have other social institutions that support children and act as a stopgap for parental failures. One justification for having a public education system, for example, is that it contributes to the child's development.

31. The trait might not actually make the child more dependent, but if the procreator thinks it will, that's still a wrong. If a procreator selects the sex of the child because she (mistakenly) thinks female children can never be fully independent, then she wrongs her child. The wrong isn't explained by the badness of the trait (it's not bad to be female), but by the motivation behind its selection.

32. McDougell (2005) proposes a virtue theory account of procreative ethics. To know whether parents should select for a trait, we should ask: what would the virtuous parent do? Wasserman (2005) suggests that we evaluate prospective parents' procreative actions by asking whether they had an appropriate parental attitude. In a similar vein, on a role-based account we should ask: are procreators acting in accordance with the end of the parental role? 
Deaf parents might also select for deafness in order to better discharge their parental obligations to their offspring. They might, for example, anticipate having a harder time equipping a hearing child to navigate the world as an independent agent, partly because the child would grow up in a community organized around deafness. And while hearing parents might face serious challenges raising a deaf child, deaf parents are uniquely positioned to help a deaf child understand the world as he will experience it. 33 They might select for deafness, then, both for the child's sake and to better position themselves to be good parents.

On the role-based framework I've proposed, selecting for deafness remains a difficult case, but its difficulty isn't unfamiliar. Like all parents, prospective parents must make judgements about what's best for their children, but we don't always agree about what the child's best interest is. This problem isn't unique to selection. The scope of parental authority is an evolving issue, one that reflects the social nature of the parental role. We are constantly negotiating and renegotiating what authority parents have to make choices for their children. To care for their children, they need some authority to make choices for them, but they aren't thereby free to decide whatever they like, however they like. On the rolebased account, procreative choices, including selection decisions, should be part of our ongoing negotiation of the parental role.

Deaf parents who select for deafness because they think it's in their child's interest, or because they think it will better enable them to be good parents to the child, at least act for the right kind of (parental) reason. Even if they're wrong about what's in the interest of the child, they're not making the mistake of the wealthy man or the self-regarding non-identity procreators. They take their role obligation to act on behalf of their child's interest to be action-guiding.

Even without a clear verdict on the permissibility of selecting for deafness or other disabilities, the role-based framework can help us rule out other justifications for disability selection that are inadequate. For instance, selecting for a disability as a means to grow the community of persons with that disability isn't the right kind of reason to justify a choice on behalf of one's future child. Prospective parents shouldn't enter the parental role with a child merely as a means to serve the interests of some group. ${ }^{34}$ Nor should prospective parents select for deafness to, by way of a permanent physical trait, ensure that their children will be members of their own cultural community. Parents may have a legitimate interest in sharing what they care about with their children as part

33. Davis (1997) points out that the education and income disparities between deaf and hearing persons are largely the result of deaf children being born to hearing parents.

34. This justification implicates more than genetic selection. To have a child simply to grow some community, to acquire laborers for the farm, etc., is a failure to act well as that child's parent. This failure doesn't require that the child suffer some bad outcome, just that the prospective parent fails to be guided by her obligations as a prospective parent. 
of the parent-child relationship, but they do not have a blanket permission to do whatever they can to ensure that their child will come to share their beliefs and values. Indoctrinating one's child can make it easier to include him in one's religious practices and to ensure his continued participation, but that doesn't permit a parent to indoctrinate her child. ${ }^{35}$ In the same way, deaf parents are not permitted to select for deafness as a way of ensuring that their children remain a part of the Deaf community.

If deaf parents are permitted to select for a disability, or any trait, their selection should be justifiable from within the parental role, and they should condition their selection on its being justifiable from within the parental role. Good parenting is as much about acting for the right reasons as it is acting in the right way. Selecting for deafness (or any other trait) may sometimes be permissible, but not all reasons for selecting for deafness are acceptable. Insofar as procreators are creating children to parent, they are bound by parental obligations and so must act for the sake of their child, not just themselves or their community. What procreators may select for, then, is a question about the extent of parental authority to make choices for their children, not simply a question about whether it's better or worse for a child to be brought into existence with that trait.

\section{Conclusion}

Using a role-based framework in procreation cases allows us to think about the morality of procreation in terms of the relation between procreators and their offspring without first locating a harm to the person created. Certain kinds of procreative actions may not be justifiable with respect to the obligations that parents have to their future children, whether or not the children they create are harmed or put at risk of harm. Procreators can wrong their offspring even if their actions ultimately benefit them, because their failure to meet their role obligations cannot be absolved by some positive outcome for their offspring. Whatever their children's ultimate wellbeing, they damage their moral relationship with them just by failing to act well as prospective parents.

Whatever account we give of parental obligations, once we're talking about procreators' obligations qua prospective parents, we've shifted the question from one about the possibility of procreative harm and the metaphysics of identity to

35. See, for example, Clayton's (2006) discussion of the competing interests of parents who want to enroll their children in their comprehensive doctrine and children's interest in making decisions about such matters for themselves (when they are capable of making such decisions). Can parents take their children to church? Can they enroll them in religious schools? The scope of parental authority to shape the beliefs and values of their children is contentious, whether it's via education or genetic selection. 
parental motivations and the appropriate limits of parental choice. Whether or not a child has been harmed by being created isn't irrelevant to the moral assessment of a procreator's action, but it is important to notice that it is not the only metric by which we can evaluate the morality of her action with respect to the person she creates. We must also ask what procreators owe their offspring qua prospective parents.

\section{Acknowledgments}

Thanks to members of UCLA's Moral Philosophy Reading Group and Stanford's Political Theory Workshop for feedback on earlier drafts of this paper. I am especially grateful to Barbara Herman, Eamonn Callan, and two anonymous referees for substantial comments on earlier versions of this paper.

\section{References}

Adams, Robert (1972). Must God Create the Best? The Philosophical Review, 81(3), 317-332. Archard, David (2010). The Obligations and Responsibilities of Parenthood. In D. Archard and D. Benatar (Eds.), Procreation and Parenthood (103-127). Oxford University Press.

Asch, Adrienne (1999). Prenatal Diagnosis and Selective Abortion: A Challenge to Practice and Policy. American Journal of Public Health, 89(11), 1649-1657.

Barnes, Elizabeth (2014). Valuing Disability, Causing Disability. Ethics, 125(1), 88-113.

Baruch, Susannah (2007). Preimplantation Genetic Diagnosis and Parental Preferences: Beyond Deadly Disease. Houston Journal of Health Law and Policy, 8(2), pp. 245-270.

Blackstone, William (1803). Of Parent and Child. In Commentaries on the Laws of England, in Four Books (434-447). A. Strahan.

Brennan, Samantha (2014). The Goods of Childhood and Children's Rights. In F. Baylis and C. McLeod (Eds.), Family-Making: Contemporary Ethical Challenges (29-48). Oxford University Press.

Brock, Dan (1995). The Non-Identity Problem and Genetic Harms: The Case of Wrongful Handicaps. Bioethics, 9(3-4), 269-275.

Buchanan, Allen, Dan W. Brock, Norman Daniels, Daniel Wikler (2000). From Chance to Choice: Genetics and Justice. Cambridge University Press.

Clayton, Matthew (2006). Parents and Public Reason. In Justice and Legitimacy in Upbringing (87-128). Oxford University Press.

Cohen, G. A. (1967). Beliefs and Rôles. Proceedings of the Aristotelian Society, 67(1), 17-34.

Davis, Dena (1997). Genetic Dilemmas and the Child's Right to an Open Future. The Hastings Center Report, 27(2), 7-15.

Dolnick, Edward (1993). Deafness as Culture. The Atlantic Monthly, 272(3), 37-53.

Feinberg, Joel (1980). The Child's Right to an Open Future. In William Aikenand Hugh LaFollette (Eds.), Whose Child? (124-153). Rowman \& Littlefield. 
Feldman, Susan (1992). Multiple Biological Mothers: The Case for Gestation. Journal of Social Philosophy, 23(1), 98-104.

Fuscalda, Giulianna (2006). Genetic Ties: Are They Morally Binding? Bioethics, 20(2), 6476.

Hall, Barbara (1999). The Origin of Parental Rights. Public Affairs Quarterly, 13(1), 73-82.

Hannan, Sarah and Richard Vernon (2008). Parental Rights: A Role-Based Approach. Theory and Research in Education, 6(2), 173-189.

Hanser, Matthew (1990). Harming Future People. Philosophy and Public Affairs, 19(1), 4770.

Harman, Elizabeth (2004). Can We Harm and Benefit in Creating? Philosophical Perspectives, 18(1), 89-113.

Hill, John L. (1991). What Does It Mean to Be a 'Parent'? The Claims of Biology as a Basis for Parental Rights. New York University Law Review, 66(2), 353-420.

Horton, John (1992). Political Obligation. Macmillan.

Hurley, Paul and Rivka Weinberg (2015). Whose Problem is Non-Identity. Journal of Moral Philosophy, 12(6), 699-730.

Joffe, Steven and Robert D. Truog (2010). Consent to Medical Care: The Importance of Fiduciary Context. In F. G. Miller and A. Wertheimer (Eds.), The Ethics of Consent (347-374). Oxford University Press.

Kant, Immanuel (1997). Groundwork of the Metaphysics of Morals (Mary Gregor, Ed. and Trans.). Cambridge University Press.

Kavka, Gregory (1982). The Paradox of Future Individuals. Philosophy \& Public Affairs, $11(2), 93-112$.

Kumar, Rahul (2003). Who Can Be Wronged? Philosophy \& Public Affairs, 31(2), 99- 118.

Lafollette, Hugh (1980). Licensing Parents. Philosophy \& Public Affairs, 9(2) 182- 197.

May, Simon (2015). Directed Duties. Philosophy Compass, 10(8), 523-532.

McDougell, Rosalind (2005). Acting Parentally: An Argument against Sex Selection. Journal of Medical Ethics, 31(10), 601-605.

McMahan, Jeff (2005). Causing Disabled People to Exist and Causing People to Be Disabled. Ethics, 116(1), 77-99.

Millum, Joseph (2010). How Do We Acquire Parental Rights? Social Theory and Practice, 36(1), 112-132.

Mindness, Anna (Ed.) (2006). Reading between the Signs: Intercultural Communication for Sign Language Interpreters. Intercultural Press.

Parfit, Derek (1976). On Doing the Best for Our Children. In Michael Bayles (Ed.), Ethics and Population (100-115). Schenkman.

Parfit, Derek (1987). Reasons and Persons. Clarendon Press.

Parker, Philip (1982). Surrogate Motherhood: The Interaction of Litigation, Legislation, and Psychiatry. International Journal of Law and Psychiatry, 5(3), 341-354.

Reich, Rob (2002). Bridging Liberalism and Multiculturalism in American Education. Chicago University Press.

Sandel, Michael (2007). The Case Against Perfection. Harvard University Press. 45-62

Savulescu, Julian (2002). Deaf Lesbians, 'Designer Disability,' and the Future of Medicine. British Medical Journal, 325(7367), 771-773.

Savulescu, Julian and Guy Kahane (2009). The Moral Obligation to Create Children with the Best Chance of the Best Life. Bioethics, 23(5), 274-290.

Schapiro, Tamar (1999). What is a Child? Ethics, 109(4), 715-738. 
Sciaraffa, Stefan (2011). Identification, Meaning, and the Normativity of Social Roles. European Journal of Philosophy, 19(1), 107-128.

Shiffrin, Seana V. (1999). Wrongful Life, Procreative Responsibility, and the Significance of Harm. Legal Theory, 5(2), 117-148.

Simmons, A. John (1996). External Justifications and Institutional Roles. Journal of Philosophy, 93(1), 28-36.

Thompson, Charis (2005). Making Parents: The Ontological Choreography of Reproductive Technologies. MIT Press.

Velleman, David J. (2008). Persons in Prospect. Philosophy \& Public Affairs, 36(3), 221-288

Wasserman, David (2005). The Nonidentity Problem, Disability, and the Role Morality of Prospective Parents. Ethics, 116(1), 132-152.

Woodward, James (1986). The Non-Identity Problem. Ethics, 96(4), 804-831. 